\title{
ROOT CANAL MORPHOLOGY OF MANDIBULAR PREMOLARS IN NORTH INDIAN POPULATION USING TOOTH CLEARING TECHNIQUE - AN IN VITRO STUDY
}

Gurkirat Singh Grewal $^{1}$, Ajay Chhabra ${ }^{2}$, Varun Jindal ${ }^{3}$, Simran Pal Singh Bindra ${ }^{4}$, Vandana Chhabra ${ }^{5}$ Damanpreet $^{6}$

${ }^{1}$ Senior Lecturer, Department of Conservative Dentistry \& Endodontics, Bhojia Dental College \& Hospital, Himachal Pradesh, India

${ }^{2}$ Professor \& Head, Department of Conservative Dentistry \& Endodontics, Bhojia Dental College \& Hospital, Himachal Pradesh, India

${ }^{3}$ Reader, Department of Conservative Dentistry \& Endodontics, Bhojia Dental College \& Hospital, Himachal Pradesh, India

${ }^{4}$ P.G. Student, Department of Conservative Dentistry \& Endodontics, Bhojia Dental College \& Hospital, Himachal Pradesh, India

${ }^{5}$ Reader, Department of Oral and Maxillofacial Surgery, SKSS Dental College, Punjab, India

${ }^{6}$ Reader, Department of Conservative Dentistry \& Endodontics, Bhojia Dental College \& Hospital, Himachal Pradesh, India

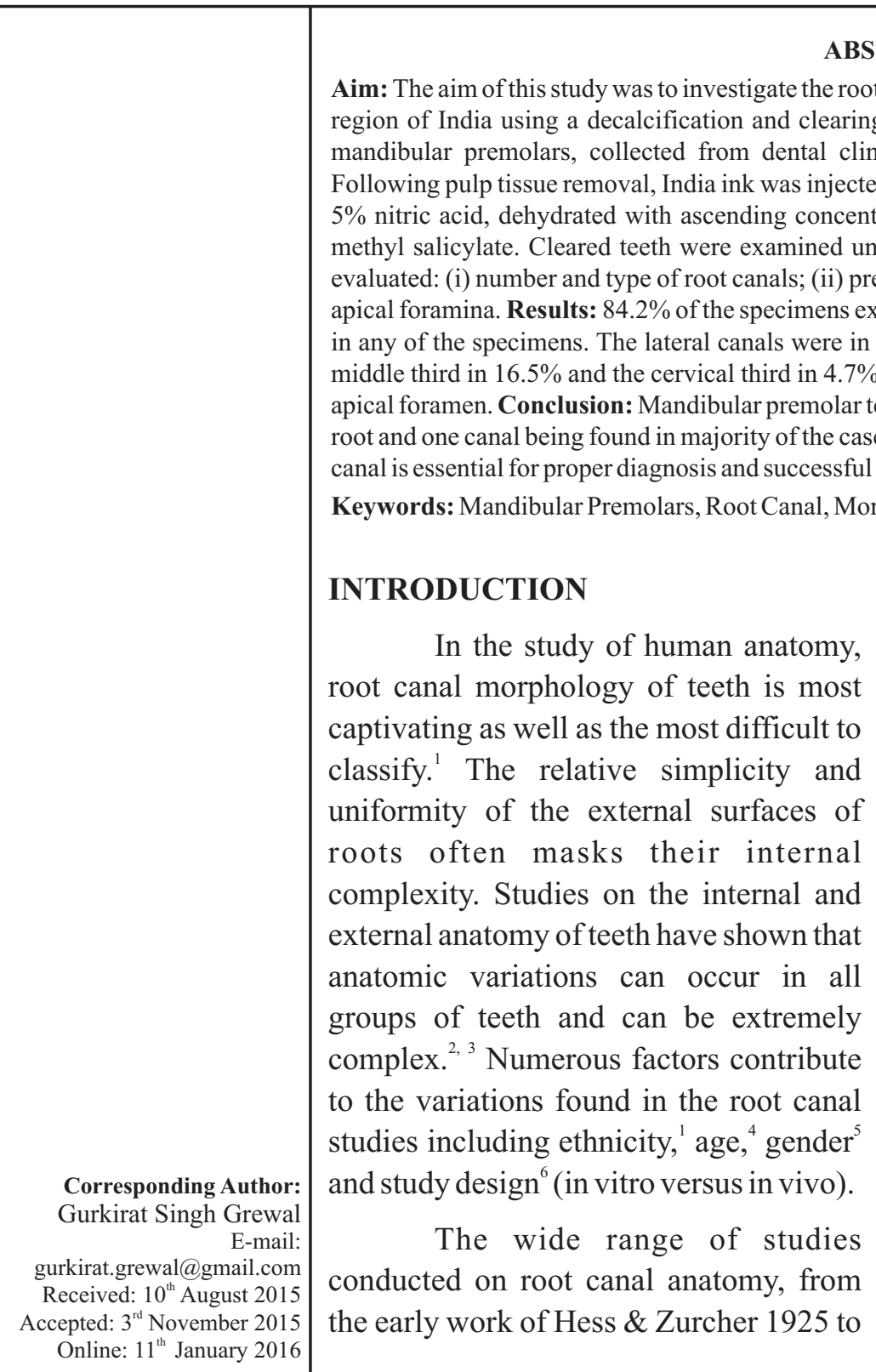

ABSTRACT

Aim: The aim of this study was to investigate the root canal morphology of mandibular premolars in Northern and clearing technique. Method: Three hundred extracted human dental clinics within North India were selected for this study. canal is essential for proper diagnosis and successful treatment of endodontic cases.

\section{INTRODUCTION}

root canal morphology of teeth is most captivating as well as the most difficult to classify. The relative simplicity and uniformity of the external surfaces of roots often masks their internal external anatomy of teeth have shown that anatomic variations can occur in all groups of teeth and can be extremely studies including ethnicity, age, ${ }^{4}$ gender The wide range of studies Online: $11^{\text {th }}$ January 2016 the most recent, ${ }^{1,5}$ demonstrating anatomic complexities of the root canal system, have all emphasized on the fact that a root with a graceful, tapering canal and a single apical foramen is an exception rather than the rule. ${ }^{7}$ Allen et al ${ }^{8}$ stated that even though the complex webs, fins and communications do not contribute significantly to outcome, it is clear that many factors including knowledge of canal numbers and divisions may contribute to the predictability of overall endodontic treatment.

Brescia 1961 reported that the mandibular first premolar teeth had the most variable canal pattern. ${ }^{9}$ A study at the University of Washington 1955 assessed the failure rate of non surgical root canal treatment in all teeth. The mandibular first 
premolar had the highest failure rate in the study at $11.45 \%$. Possible reasons for this conclusion are the numerous variations in root canal morphology and difficult access to additional canal systems when present. ${ }^{10}$ Slowey has suggested that mandibular first premolars, often called as "Endodontic enigma," may present the greatest difficulty of all teeth to perform successful endodontic treatment. ${ }^{11}$

The studies on root canal morphology of mandibular premolars were mainly performed in United States of America, ${ }^{3,12,13,14}$ China, ${ }^{15,16,17,18}$ Sweden, ${ }^{19}$ Turkey, ${ }^{5,20,21}$ United Kingdom, ${ }^{22,23}$ Austria $^{24}$ New Zealand, ${ }^{25}$ Poland ${ }^{26}$ and Iran. ${ }^{27}$

Asian populations present one of the widest variations in coronal shape, external root form and internal canal space morphology. ${ }^{28}$ It is therefore considered important to be familiar with variations in tooth/canal anatomy and characteristic features in various racial groups. ${ }^{29}$ Such knowledge can aid location and negotiation of canals as well as their subsequent management. Studies on the root canal morphology amongst the Indian population are rare. ${ }^{30}$

A variety of techniques has been used to study the anatomy of the root canal system. These techniques have included decalcification and clearing, ${ }^{1,3,7}$ direct observation with microscope, ${ }^{31}$ radiography, ${ }^{32}$ sectioning and macroscopic observation, ${ }^{15,33} 3 \mathrm{D}$ reconstruction, ${ }^{34}$ contrast medium-enhanced radiography ${ }^{35,36}$ and more recently computed tomographic techniques. ${ }^{17,24,29,36-38}$ The other techniques that had also been used are grinding out of teeth, metal filling of pulp cavities and corrosion, iontophoresis, injections and plastic embeddings. ${ }^{39}$

The present study was conducted using the decalcification and tooth clearing technique because it is considered as the gold standard ${ }^{38}$ for analyzing the root canal anatomy. Vertucci ${ }^{40}$ has also reported that the most detailed information can be obtained ex vivo by demineralization and staining. Unlike radiographic images, the clearing technique provides a threedimensional view of the pulp cavity in relation to the exterior of the teeth and allows a comprehensive examination of the pulp chamber and root canal system. ${ }^{41}$
A few studies on mandibular premolars have been carried out in India like Gujarat ${ }^{28}$ and Chennai. ${ }^{92-43,}$ Sikri et $\mathrm{al}^{44}$ evaluated the root canal morphology of mandibular premolars in Amritsar (Punjab). No other data is available on root canal morphology of mandibular premolars in northern region of India.

Therefore, the following study was conducted to investigate, in detail, the root canal morphology of mandibular premolars in Northern region of India using a decalcification and clearing technique.

\section{MATERIALSAND METHODS}

A total of 300 extracted mandibular premolars were randomly collected from general dental clinics within North India. The gender and age of patients was unknown, and no attempt was made to differentiate between first and second mandibular premolars. Hard and soft deposits were removed using hand-scaling instruments scrubbed under tap water. Teeth with root fractures $(n=3)$, immature apices $(n=10)$, root caries $(n=5)$ and resorption $(n=2)$ were excluded. The samples were stored in 5.25\% sodium hypochlorite (Dentpro, Amrit chemicals Ltd, Mohali, Punjab, India) for 30 minutes for the removal of organic debris and then in $10 \%$ formaldehyde until further steps.

The pulp chambers were assessed using round bur (Mani) and Endo Z bur (Dentsply International) in a high speed handpiece (NSK, Japan) and the pulp tissue was removed from the canal orifices with the No. $10 \mathrm{~K}$ file (Mani). India ink (Himedia Laboratories Pvt. Ltd., Mumbai, India) was injected into the root canals using syringes with a 27 gauge needle (Sterican, Braun Medical India Pvt. Ltd., Mumbai, India) under negative pressure at the apical end.

Samples were then kept in 5\% nitric acid solution (Aries Laboratories, Ahmedabad, India) for 5 days. The solution was changed daily while agitating it three times a day. Demineralisation was assessed with the help of Radiovisiography. The teeth were then rinsed under running water for 4 hours and dehydrated in solutions of $70 \%, 80 \%$ and $95 \%$ ethyl alcohol successively for 24 hours. At the end of this period, no radiopacity was observed. 
Samples were then placed in methyl salicylate (Vikas Pharma, Mumbai, India) to enhance the translucency. At the end of the third day, complete transparency was achieved.

Teeth in which dye did not penetrate till the apical end were excluded ( $\mathrm{n}=5)$.

The samples were then examined under Stereomicroscope (5X) (Olympus, Tokyo, Japan), and the following observations were made:

(i) Type of root canals

(ii) Presence and location of lateral canals

(iii) Location of apical foramina

Canals were categorised according to Vertucci's ${ }^{40}$ classification (Figure 1) as follows:

The samples that were not included in Vertucci's ${ }^{40}$ Classification 1984 were categorised according to Gulabivala's ${ }^{1}$ Classification 2001 ( $n=2$; Figure 2) and Sert \& Bayirli's classification $2004(n=1$; Figure 3).

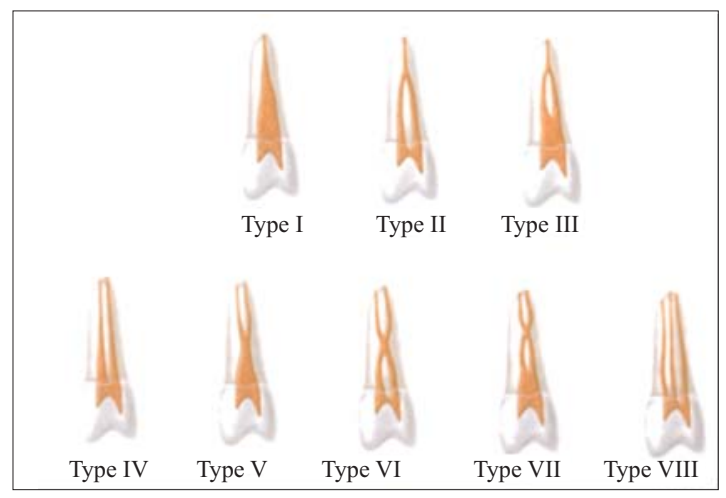

Figure 1: Vertucci's Classification

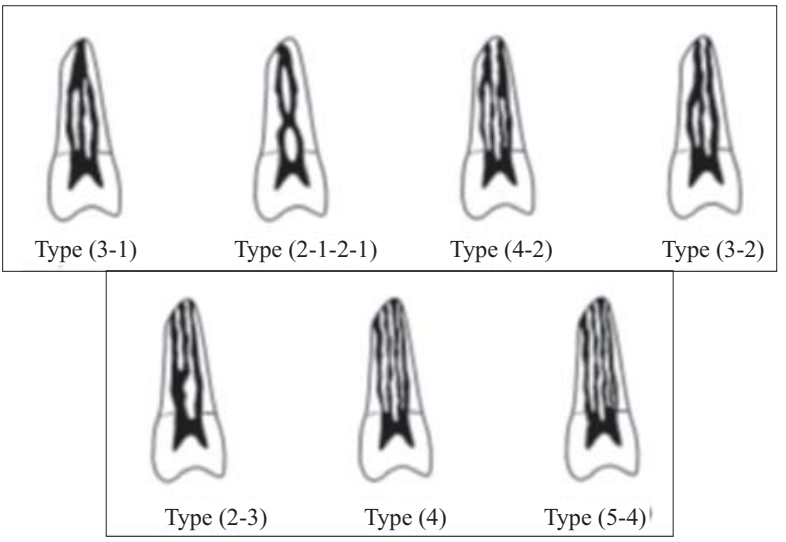

Figure 2: Gulabivala's Classification

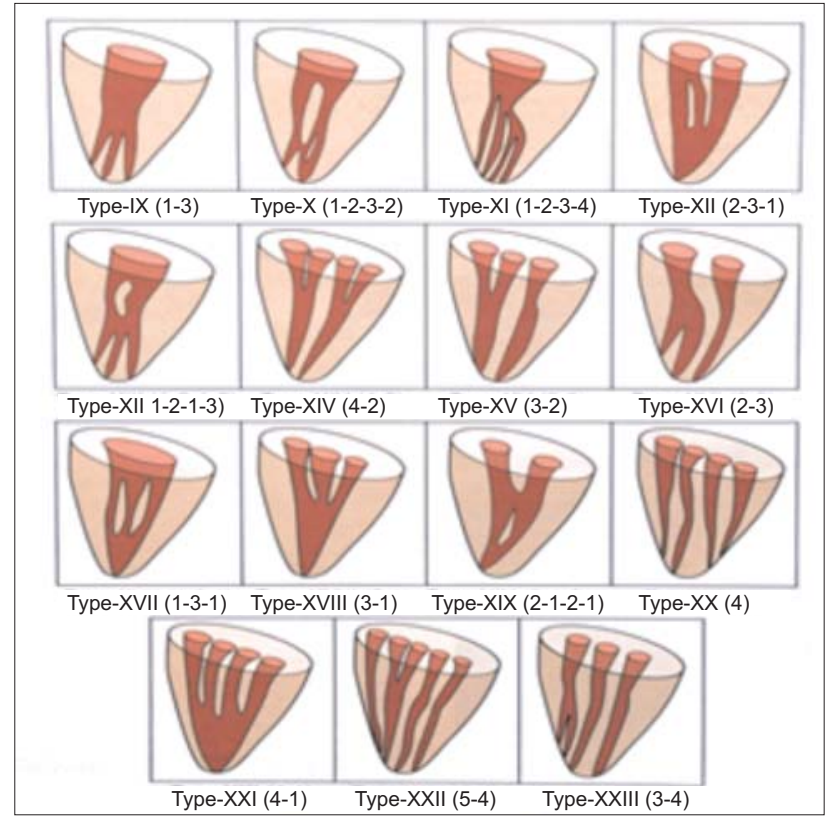

Figure 3: Sert and Bayirli's additional canal types

\section{RESULTS}

$84.2 \%$ of the specimens exhibited Type I canal pattern. Type $\mathrm{V}$ was the second most common canal pattern as observed in $10.3 \%$ of the specimens. Type II, Type III, Type IV canal patterns were evident in $1.5 \%, 1.8 \%$, $1.1 \%$ of the specimens. $0.7 \%, 0.4 \%$ of the samples stained Type VI, Type VII canal pattern. Type VIII was not observed in any of the specimens (Table 1; Figure 4).

Table 1: Type \& Number of Root Canals

\begin{tabular}{|l|c|c|}
\hline Type & Number of teeth & Percentage \\
\hline Type I & 229 & 84.2 \\
\hline Type II & 4 & 1.5 \\
\hline Type III & 5 & 1.8 \\
\hline Type IV & 3 & 1.1 \\
\hline Type V & 28 & 10.3 \\
\hline Type VI & 2 & 0.7 \\
\hline Type VII & 1 & 0.4 \\
\hline Type VIII & Zero & Zero \\
\hline
\end{tabular}

Of 272 samples in the study, lateral canals were observed in 127 teeth (46.7\%). The lateral canals were found most often in the apical third (78.7\%) followed by middle third $(16.5 \%)$ and the cervical third (4.7\%) (Table 2). 


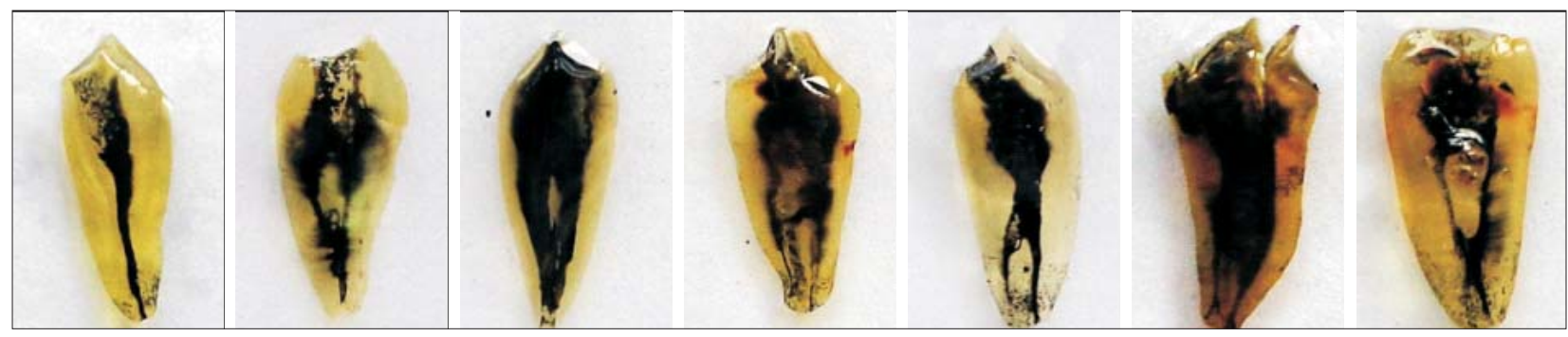

Figure 4: Types of Root Canal's According to Vertucci

Table 2: Presence and location of lateral canals

\begin{tabular}{|l|c|c|}
\hline Position of lateral canals & No. of teeth & Percentage \\
\hline Cervical & 6 & 4.7 \\
\hline Middle & 21 & 16.5 \\
\hline Apical & 100 & 78.7 \\
\hline
\end{tabular}

The apical foramen was found to coincide with the apical root tip only in $17.3 \%$ of the cases. Majority of the specimens $(82.7 \%)$ show lateral position of the apical foramen (Table 3).

Table 3: Location of apical foramen

\begin{tabular}{|c|c|c|}
\hline Position & No. of teeth & Percentage \\
\hline Central & 47 & 17.3 \\
\hline Lateral & 225 & 82.7 \\
\hline
\end{tabular}

\section{DISCUSSION}

The study of root and canal anatomy has endodontic and anthropological significance..$^{22,29}$ It is important to be familiar with the variations in the root canal anatomy. Slight deviations from the original root path can cause procedural accidents (ledging, perforation or root fracture) during endodontic treatment, post space preparation, and post insertion. ${ }^{32}$

The complexity of the root and root canal morphology of the mandibular first premolar may have been underestimated in the past. A thorough review of the literature reveals both complex root morphology as well as complex internal canal morphology. ${ }^{45}$ The studies by Serman and Hasselgren ${ }^{46}$ as well as the study by Trope et $\mathrm{al}^{13}$ reported higher incidences of multiple root canal in their studies (7\% and 3.1\%, respectively) compared with the averages reported in the anatomic studies (0.4\%). ElDeeb ${ }^{47}$ (1982), Shapira \& Delivanis ${ }^{48}$ (1982) and Rodig \& Hulsmann ${ }^{49}$ (2003) reported a mandibular second premolar with three canals, whereas Bram \& Fleisher $^{50}$ (1991), Wong ${ }^{51}$ (1991), Holtzman ${ }^{52}$
(1998), Rhodes ${ }^{53}$ (2001), Macri \& $\mathrm{Zmener}^{54}$ (2000) and Sachdeva GS et $\mathrm{al}^{55}$ (2008) reported cases of mandibular second premolars with four canals, some with serious clinical outcomes.

In the present study, root canal system of mandibular premolars with Type I canal pattern was found to be predominantly $84.2 \%$. The results are in concurrence with a study reported by Vertucci, ${ }^{40}$ and Sandhya, Velmurugan \& Kandaswami ${ }^{43}$ who reported an incidence of $80 \%$ in mandibular first premolars.

The present study showed Type II canal pattern in $1.5 \%$ of the teeth which is similar to the findings by Iyer $\mathrm{VH}$ et $\mathrm{al}^{56}$ ( $1 \%$ in case of mandibular premolars). Rahimi et $\mathrm{al}^{57}$ reported the incidence of Type II canal pattern in $1.9 \%$ of the mandibular first premolars, but the observations were different regarding mandibular second premolars $(7.9 \%)$.

Type III canal system was found in $1.8 \%$ of the teeth which is similar to the findings of Awawdeh \& Qudah, ${ }^{7}$ who reported Type III canal pattern in $1.4 \%$ of the mandibular first premolars and $1 \%$ in mandibular second premolars. The findings by Vertucci ${ }^{40}$ were $4 \%$ in mandibular first premolars.

Type IV canal system was found in $1.1 \%$ mandibular premolars which is in accordance with Vertucci, ${ }^{40}$ Sandhya, Velmurugan \& Kandaswami ${ }^{43}$ and Jain \& Bahuguna ${ }^{28}$ who reported this system in $1.5 \%$, $2 \%$ and $2.89 \%$ of mandibular first premolar teeth. . Iyer VH et $\mathrm{al}^{56}$ reported Type IV canal pattern in $20.8 \%$ of the mandibular premolars.

Type $\mathrm{V}$ canal pattern was the second most common canal pattern as observed in $10.3 \%$ of the specimens which is similar to study by Velumurgan \& Sandhya ${ }^{9}$ who reported an incidence of $8 \%$ in 
mandibular first premolars. Yang $\mathrm{H}$ et $\mathrm{al}^{58}$ and Caliskan $\mathrm{MK}$ et $\mathrm{al}^{20}$ reported Type $\mathrm{V}$ canal pattern in 9.32 and $9.43 \%$ of mandibular first premolars. Sert, Aslanap \& Tanalp $^{21}$ reported Type V canal pattern in $7 \%$ of the mandibular second premolars.

$0.7 \%$ of the samples stained Type VI canal pattern which is in concurrence with the findings by Jain \& Bahuguna ${ }^{28}$ and Awawdeh \& Qudah $^{7}$ who reported incidence of $0.72 \%$ and $0.8 \%$ in case of mandibular first premolars. Vertucci ${ }^{40}$ did not report Type VI canal pattern in mandibular premolar teeth.

Type VII canal pattern was found in $0.4 \%$ of the teeth. The results are similar to the studies by Rahimi et $\mathrm{al}^{57}$ who reported Type VII canal pattern in $0.6 \%$ of the mandibular first premolars and none in mandibular second premolars. Vertucci ${ }^{40}$ and Caliskan MK et $\mathrm{al}^{20}$ reported $0 \%$ incidence of Type VII canal pattern in mandibular first and second premolars.

Type VIII canal pattern was not observed in any of the specimens. Rahimi et $\mathrm{al}^{57}$ also did not observe Type VIII canal pattern in mandibular premolars. Sandhya, Velmurugan \& Kandaswami ${ }^{43}$ and Jain \& Bahuguna $^{28}$ failed to observe Type VIII canal pattern in mandibular first premolars. Vertucci ${ }^{40}$ reported Type VIII canal pattern in $0.5 \%$ of the mandibular first premolars and none in mandibular second premolars.

The two samples that fell into Gulabivala's classification consisted of Type (3-1) and Type (2-1-21) canal pattern (Figure 5). The remaining one specimen consisted of Sert \& Bayirli's Type IX canal pattern (Figure 6).
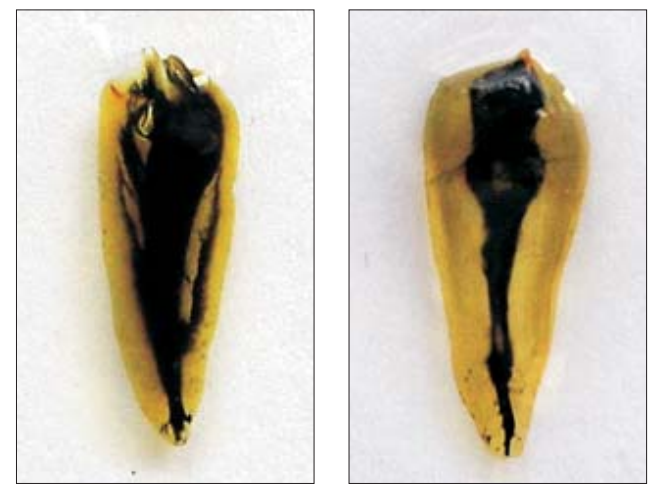

Figure 5: Gulabivala's Type (3-1) \& (2-1-2-1) canal pattern
Lateral canals were observed in $46.7 \%$ of the teeth in the present study. The lateral canals were found predominantly in the apical third $(78.7 \%$; Figure 7$)$ followed by middle third (16.5\%; Figure 8$)$ and the cervical third (4.7\%; Figure 9). The findings of the study are in concurrence with a study reported by Vertucci ${ }^{40}$ who reported the presence of lateral canals in $44.3 \%$ of mandibular first premolars and $48.3 \%$ in mandibular second premolars.

The present study showed the apical foramen to coincide with the apical root tip only in $17.3 \%$ of the cases (Figure 10) while $82.7 \%$ of the specimens showed lateral position of the apical foramen (Figure 11). The findings are similar to the study by Vertucci ${ }^{40}$ which reported location of the apical foramen on the lateral side in $85 \%$ of the mandibular first premolars and $83.9 \%$ in mandibular second premolars. Apex was

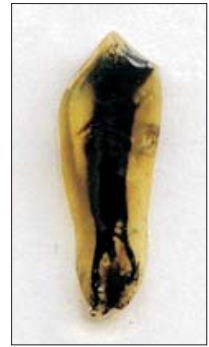

Figure 6: Sert \& Bayirli's Type IX canal pattern

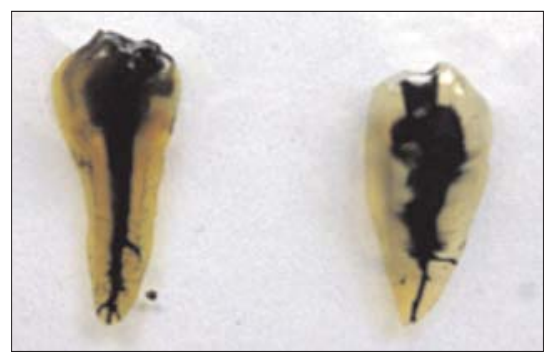

Figure 8: Lateral canals at the middle third

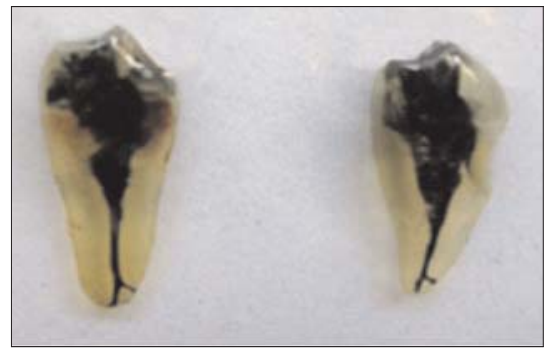

Figure 7: Lateral canals at the apical third

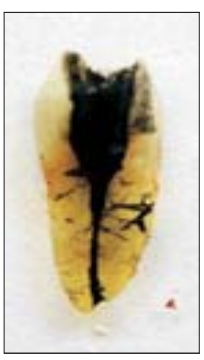

Figure 9: Lateral canals at the coronal $\&$ middle third located at the centre in $15 \%$ of the mandibular first premolars and $16.1 \%$ of the mandibular second premolars.

The difference in the incidence of the root canal system, presence and position of lateral canals 


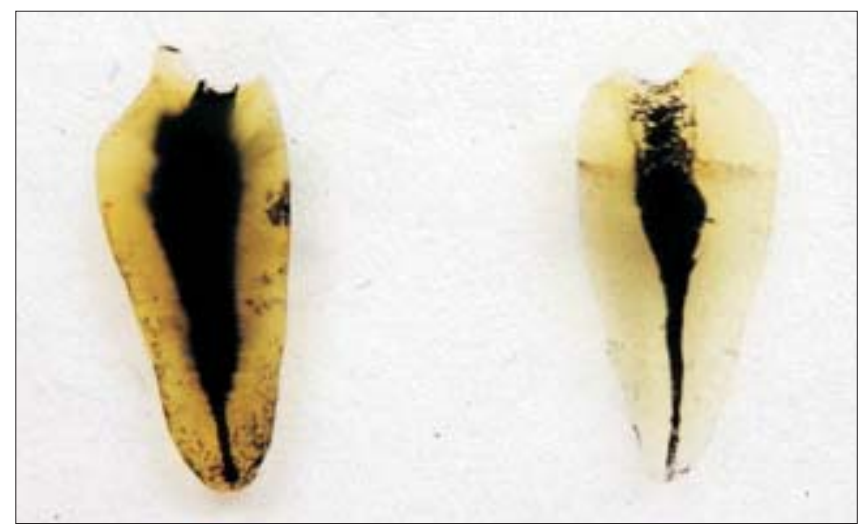

Figure 10: Apical foramen located at the centre

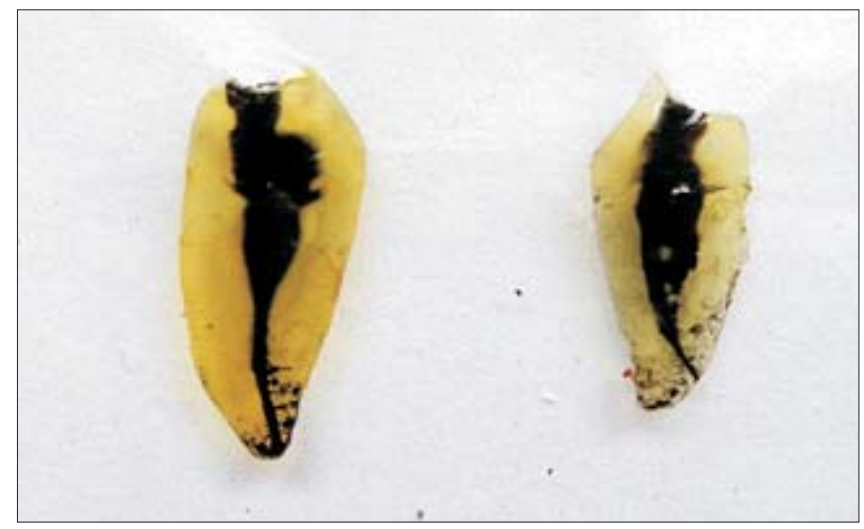

Figure 11: Lateral exit of the apical foramen

and apical foramen in the present study and those compared with could be attributed to racial difference. Different studies have looked at the root canal morphology of mandibular premolars over the years and pointed out that the root canal types may vary according to race $\mathrm{e}^{5,13,59,60}$

The most detailed three dimensional evaluation can be obtained by demineralization and staining. ${ }^{40,61}$ The technique is simple to perform, rapid and gives good results in few days. The complete penetration of dye was achieved using negative pressure of 60 Torr at the apical end as suggested by Antonopoulos, Attin and Hellwig. ${ }^{62}$ Incomplete or uneven decalcification was avoided in the present study by agitation of acid three times a day, having sufficient volume of acid, daily changes of acid solution, and not stacking teeth during demineralization as demineralization occurs more rapidly at the top of the container than at the bottom. Methyl salicylate tolerates more water and is less noxious than other clearing agents such as xylene. ${ }^{63}$

\section{CONCLUSION}

An accurate knowledge of the morphology of the pulp cavity is essential before an endodontic procedure can be approached rationally. The dentist also should be aware of the possible existence of bifurcated and double canals if root canal therapy unexpectedly fails. A thorough knowledge of these variations will assist the dentist in reaching conclusions when diagnosing and treating endodontic cases.

\section{REFERENCES}

1. Gulabivala K, Anug TH, Alavi A, Ng Y-L. Root and canal morphology of Burmese mandibular molars. Int Endod $\mathrm{J}$ 2001;34:359-370

2. Cohen S, Burns RC. Pathways of the Pulp. 5th ed. St. Louis: Mosby; 2002.p. 173-228

3. Vertucci FJ. Root canal morphology and its relationship to endodontic procedures. Endodontic Topics 2005;10:3-29

4. Neaverth EJ, Kotler LM, Kaltenbach RF. Clinical investigation (in vivo) of endodontically treated maxillary first molars. J Endod 1987;13(10):506-512

5. Sert S, Bayirli GS. Evaluation of the root canal configurations of the mandibular and maxillary permanent teeth by gender in the Turkish population. J Endod 2004;30(6):391-398

6. Awawdeh L, Abdullah H, Al-Qudah A. Root form and canal morphology of Jordanian maxillary first premolars. J Endod 2008;34(8):956-961

7. Awawdeh LA, Al-Qudah AA. Root form and canal morphology of mandibular premolars in a Jordanian population. Int Endod J 2008;41:240-248

8. Allen RK, Newton CW, Brown CE. A statistical analysis of surgical and non-surgical endodontic retreatment cases. J Endod 1989;15(6):261-266

9. Velmurugan N, Sandhya R. Root canal morphology of mandibular first premolars in an Indian population: a laboratory study. Int Endod J 2009;42:54-58

10. Ingle J, Bakland L. Endodontics, 5th ed. Hamilton: BC Decker, 2002

11. Kararia N, Chaudhary A, Kararia V. Mandibular left first premolar with two roots: A morphological oddity. Contemp Clin Dent 2012;3(2):234-236

12. Barrett MT. The internal anatomy of the teeth with special reference to the pulp with its branches. Dent Cosmos 1925;67(6):581-592 
13. Trope M, Elfenbein L, Tronstad L. Mandibular premolars with more than one root canal in different race groups. J Endod 1986;12(8):343-345

14. Gullickson DC, Montgomery S. The study of root canal morphology using a digital image processing technique. J Endod 1987;13(4):158-163

15. Lu TY, Yang SF, Pai SF. Complicated root canal morphology of mandibular first premolar in a Chinese population using the cross section method. J Endod 2006;32(10):932-936

16. Walker RT. Root canal anatomy of mandibular first premolars in a southern Chinese population. Endod Dent Traumatol 1988;4:226-228

17. Fan B, Yang J, Gutmann JL, Fan M. Root canal systems in mandibular first premolars with $\mathrm{C}$-shaped root configurations. Part I: Microcomputed tomography mapping of the radicular groove and associated root canal cross-sections. J Endod 2008;34 (11):1337-1341

18. Fan B, Ye W, Xie E, Wu H, Gutmann JL. Three-dimensional morphological analysis of C-shaped canals n mandibular first premolars in a Chinese population. Int Endod J 2012;45:10351041

19. Kerkes K, Tronstad L. Morphometric observations on root canals of human premolars. J Enod 1977;3(2):74-79

20. Caliskan MK, Pehlivan Y, Sepetcioglu F, Turkun M, Tuncer SS. Root canal morphology of human permanent teeth in a Turkish population. J Endod 1995;21(8):200-204

21. Sert S, Aslanalp V, Tanalp J. Investigation of the root canal configurations of mandibular permanent teeth in the Turkish population. Int Endod J 2004;37:494-499

22. Bedford JM, Martin DM, Youngson CC. Assessment of a contrast medium as an adjunct to endodontic radiography. Int Endod J 2004;37:806-813

23. Nattress BR, Martin DM. Predictability of radiographic diagnosis of variations in root canal anatomy in mandibular incisor and premolar teeth. Int Endod J 1991;24:58-62

24. Robinson S, Czerny C, Gahleitner A, Bernhart T, Kainberger FM. Dental CT evaluation of mandibular first premolar root configurations and canal variations. Oral Surg Oral Med Oral Pathol Oral Radiol Endod 2002;93:328-332

25. Kelsen AE, Love RM, Kieser JA, Herbison P. Root canal anatomy of anterior and premolar teeth in Down's syndrome. Int Endod J 1999;32:211-216

26. Kusiak A, Sadlak-Nowicka J, Limon J, Kochanska B. Root morphology of mandibular premolars in 40 patients with Turner syndrome. Int Endod J 2005;38:822-826
27. Khedmat S, Assadian $\mathrm{H}$ and Saravani AA. Root canal morphology of the mandibular first premolars in an Iranian population using cross-sections and radiography. J Endod 2010;36(2):214-217

28. Jain A, Bahuguna R. Root canal morphology of mandibular first premolar in a Gujarati population-an in vitro study. Dent Res J 2011;8(3):118-122

29. Walker RT. Root form and canal anatomy of mandibular first molars in a Southern Chinese population. Endod Dent Traumatol 1988;4:19-22

30. Reuben J, Velmurugan N, Kandaswamy D. The evaluation of root canal morphology of the mandibular first molar in an Indian population using spiral computed tomography scan: An in vitro study. J Endod 2008;34(2):212-215

31. Sempire HN, Hartwell GR. Frequency of second mesiobuccal canals in maxillary molars as determined by use of an operating microscope: A clinical study. J Endod 2000;26(11):673-674

32. Willershausen B, Tekyatan H, Kasaj A, Marroquin BB. Roentgenographic in vitro investigation of frequency and location of curvatures in human maxillary premolars. J Endod 2006;32(4):307-311

33. Baisden MK, Kulild JC, Weller RN. Root canal configuration of the mandibular first premolar. J Endod 1992;18(10):505508

34. Mikrogeorgis G, Lyroudia KL, Nikopoulos N, Pitas I, Molyvdas I, Lambrianidis TH. 3D computer-aided reconstruction of six teeth with morphological abnormalities. Int Endod J 1999;32:88-93

35. Fan B, Gao Y, Fan W, Gutmann JL. Identification of a Cshaped canal system in mandibular second molars-part II: The effect of bone image superimposition and intraradicular contrast medium on radiograph interpretation. J Endod 2008;34(2):160-165

36. Neelakantan P, Subbarao C, Subbarao CV. Comparative evaluation of modified canal staining and clearing technique, cone beam computed tomography, peripheral quantitative computed tomography, spiral computed tomography, and plain and contrast medium-enhanced digital radiography in studying root canal morphology. J Endod 2010;36(9):15471551

37. Sberna MT, Rizzo G, Zacchi E, Cappare P, Rubinacci A. A preliminary study of the use of peripheral quantitative computed tomography for investigating root canal anatomy. Int Endod J 2009;42:66-75

38. Kim Y, Lee S-J, Woo J. Morphology of maxillary first and second molars analyzed by cone-beam computed tomography 
in a Korean population: Variations in the number of roots and canals and the incidence of fusion. J Endod 2012;38(8):10631068

39. Deus QDD, Horizonte B. Frequency, location and direction of the lateral, secondary and accessory canals. J Endod 1975;1(11):361-366

40. Vertucci FJ. Root canal anatomy of human permanent teeth. Oral Surg 1984;58:589-599

41. Vertucci FJ. Root canal morphology of mandibular premolars. JADA 1978;97(1):47-50

42. Raj UJ, Sumitha M. Root canal morphology of maxillary second premolars in an Indian population. J Conserv Dent 2010;13(3):148-151

43. Sandhya R, Velmurugan N, Kandaswamy D. Assessment of root canal morphology of mandibular first premolars in the Indian population using spiral computed tomography: An in vitro study. Indian J Dent Res 2010;21(2):169-173

44. Sikri VK, Sikri P. Mandibular premolars: Aberrations in pulp space morphology. Ind J Dent Res 1994;5:9-14

45. Cleghorn BM, Christie WH, Dong CCS. The root and root canal morphology of the human mandibular first premolar: A literature review. J Endod 2007;33(5):509-516

46. Serman NJ, Hasselgren G. The radiographic incidence of multiple roots and canals in human mandibular premolars. Int Endod J 1992;25:234-237

47. Eldeeb ME. Three root canals in mandibular premolars: literature review and a case report. J Endod 1982;8(8):376-377

48. Shapira Y, Delivanis. Multiple-rooted mandibular second premolars. JEndod 1982;8(5):231-232

49. Rodig T, Hulsmann M. Diagnosis and root canal treatment of a mandibular second premolar with three root canals. Int Endod J 2003;36:912-919

50. Bram SM, Fleisher R. Endodontic therapy in a mandibular second bicuspid with four canals. J Endod 1991;17(10): $513-515$

51. Wong M. Four root canals in a mandibular second premolar. J Endod 1991;17(3):125-126

52. Holtzman L. Root canal treatment of mandibular second premolar with four root canals: A case report. Int Endod J 1998;31:364-366
53. Rhodes JS. A case of an unusual anatomy of a mandibular second premolar with four canals. Int Endod J 200;34:645-648

54. Macri E, Zmener O. Five canals in a mandibular second premolar. J Endod 2000;26(5):304-305

55. Sachdeva GS, Ballal S, Gopikrishna V, Kandaswamy D. Endodontic management of a mandibular second premolar with four roots and four root canals with the aid of spiral computed tomography: A case report. J Endod 2008;34(1): 104-107

56. Iyer VH, Indira $\mathrm{R}$, Ramachandran $\mathrm{S}$, Srinivasan MR. Anatomical variations of mandibular premolars in Chennai population. Ind J Dent Res 2006;17(1):7-10

57. Saeed Rahimi, Shahriar Shahi, Hamid Reza Yavari, Hakimeh Manafi, Nemat Eskandarzadeh. Root Canal Configuration of mandibular first and second premolars in an Iranian population. J Dent Res Dent Clin Dent Prospects 2007;1(2):59-64

58. Yang H, Tian C, Li G, Yang L, Han X, Wang Y. A cone-beam computed tomography study of the root canal morphology of mandibular first premolars and the location of root canal orifices and apical foramina in a Chinese population. J Endod 2013;39(4):435-438

59. Kim E, Fallahrastegar A, Hur Y-Y, Jung I-Y, Kim S, Lee S-J. Difference in root canal length between Asians and Caucasians. Int Endod J 2005;38:149-151

60. Lu TY, Yang SF, Pai SF. Complicated root canal morphology of mandibular first premolar in a Chinese population using the cross section method. J Endod 2006;32 (10):932-936

61. Sieraski SM, Taylor GN, Kohn RA. Identification and endodontic management of three-canalled maxillary premolars. J Endod 1989;15(1):29-32

62. Antonopoulos KG, Attin T, Hellwig E. Evaluation of the apical seal of root canal fillings with different methods. J Endod 1998;24 (10):655-658

63. Robertson D, Leeb J, McKee M, Brewer E. A clearing technique for the study of root canal systems. J Endod 1980;6(1):421-424

\section{Source of Support: Nil, Conflict of Interest: None Declared}

